\title{
Carriage rate of Neisseria meningitidis, antibiotic susceptibility pattern and associated risk factors among primary school children in Gondar town, Northwest Ethiopia
}

Zelalem Tefera ${ }^{1}$, Feleke Mekonnen ${ }^{2}$, Moges Tiruneh $^{3}$ and Teshome Belachew ${ }^{3 *}$ (D)

\begin{abstract}
Background: Globally, in 2012, about 1.2 million estimated cases were reported with 135,000 deaths annually. In Ethiopia, specifically in our study area, limited information is found on the oropharyngeal carriage, antimicrobial resistance pattern, and associated risk factors for $N$. meningitidis among school children. So, the aim of this study was to assess oropharyngeal carriage rate of $\mathrm{N}$. meningitidis, antibiotic susceptibility pattern and associated risk factors among primary school children in Gondar town, Northwest Ethiopia.

Methods: A cross sectional study was conducted from January to April, 2019 in Gondar town. Multi stage simple random sampling technique was used. A total of 524 oropharyngeal swabs were collected using sterile plastic cotton swabs. Modified Thayer Martin media was used for primary isolation. Antimicrobial susceptibility pattern was done based on Kirby-Bauer method on Muller-Hinton agar supplemented with 5\% sheep blood. Multidrug resistance was defined as resistance of an isolate to two or more antimicrobial classes tested. Logistic regression model was used to see the association between dependent variables (Carriage rate of Neisseria meningitidis, Serogroups of Neisseria meningitidis and Antimicrobial susceptibility patterns) and independent variables (Socio-demographic data and risk factors). Variables with a $P$ - value $\leq 0.2$ during bivariable analysis was taken to multivariable analysis to check significant association of meningococcal carriage with risk factors. Finally, a $P$-value $<0.05$ was considered as statistically significant. Data was summarized using numbers, percentages and tables.

(Continued on next page)
\end{abstract}

\footnotetext{
*Correspondence: tesh0926@gmail.com; Teshome.belachew@uog.edu.et

${ }^{3}$ Department of Medical Microbiology, School of Biomedical and Laboratory

Sciences, College of Medicine and Health Sciences, University of Gondar, Gondar, Ethiopia

Full list of author information is available at the end of the article
}

(C) The Author(s). 2020 Open Access This article is licensed under a Creative Commons Attribution 4.0 International License, which permits use, sharing, adaptation, distribution and reproduction in any medium or format, as long as you give appropriate credit to the original author(s) and the source, provide a link to the Creative Commons licence, and indicate if changes were made. The images or other third party material in this article are included in the article's Creative Commons licence, unless indicated otherwise in a credit line to the material. If material is not included in the article's Creative Commons licence and your intended use is not permitted by statutory regulation or exceeds the permitted use, you will need to obtain permission directly from the copyright holder. To view a copy of this licence, visit http://creativecommons.org/licenses/by/4.0/. The Creative Commons Public Domain Dedication waiver (http://creativecommons.org/publicdomain/zero/1.0/) applies to the data made available in this article, unless otherwise stated in a credit line to the data. 
(Continued from previous page)

Results: A total of 53(10.1\%) (Cl: 7.6-12.8) N. meningitidis isolates were identified. Serogroup A 13 (24.5\%) was the most prevalent followed by Y/W135 11(20.7\%) whereas serogroup B 4(7.6\%) was the least identified serotype. Meningococcal isolates were resistant to ciprofloxacin (45.3\%) and trimethoprim-sulfamethoxazole (73.6\%). Overall, most of meningococcal isolates showed about 32(60.4\%) multidrug resistance. Meningococcal carriage rate was significantly associated with family size, tonsillectomy, passive smoking, number of students per class, sharing utensils, history of visiting healthcare institutions, and indoor kitchen.

Conclusion: This study highlights the need for reinforcement of case-based, laboratory confirmed surveillance of $N$. meningitidis carriage in Ethiopian elementary school students to enable mapping of distribution of serotypes of the causative organisms across the country and determine the current potential necessity of vaccination.

Keywords: Carriage, N. meningitidis, School children, Antimicrobial susceptibility

\section{Background}

Neisseria meningitidis is a Gram-negative diplococci with 13 distinct serotypes. It inhabits the mucosal surface of nasopharynx and oropharynx [1]. However, about $90 \%$ of human disease are caused by serogroup A, B, C, X, Y, and W135 [2]. About 5-10\% of healthy people carry N. meningitidis in the nasopharynx and oropharynx and during epidemics, the carrier state rises to $70-80 \%$ [3]. Different factors can enhance carriage rate: Immunological susceptibility, travel, large population displacement, poor living condition, overcrowding, housing condition and climatic condition [4].

Meningococcal infection has been a big threat for the globe and exists as sporadic, hyper-sporadic, and epidemic disease. In 2012, an estimated 1.2 million cases of meningococcal infection per year was reported, with 135,000 deaths worldwide [5]. The African meningitis belt is more affected area of bacterial meningitis characterized by distinct seasonal patterns. The disease incidence peaks in the dry season [6]. In Ethiopia, a major epidemic was recorded in 2001with 6964 cases and 330 deaths. Another epidemic was also recorded in 20032004 with 3326 cases and 160 deaths [7]. In 2017, a study was done in Addis Ababa, Ethiopia among school children and $20.4 \%$ of $N$. meningitidis carriage was documented [8].

Meningococcal infection can be prevented through taking different measures and vaccination can play a pivotal role. As the result, in 2010, scientists developed the new conjugate vaccine, MenAfrivac vaccine, and implemented in sub-Saharan Africa. This vaccine is developed from, $N$. meningitidis serogroup A capsular polysaccharide and vaccination was implemented among 1-29 years old individuals [9]. Mass vaccination campaign with the same vaccine was also practiced in Ethiopia, and vaccination has been implemented in 3 phases from 2013 to 2015 [10]. In the study area, limited information is found on the oropharyngeal carriage, antimicrobial resistance pattern and associated risk factors for $N$. meningitidis especially in school children. Thus, carriage studies are important to improve our understanding of the $N$. meningitidis serogroup distribution and also the epidemiology of meningococcal disease control. Thus, it is important to determine the percentage of carriage rates. If the rate of carriers were identified, then tools to reduce personal contacts could be provided in populations with a high carrier rate. This process may include avoidance of crowding, reconstruction of the air-condition systems of the dorms, personal health education, or the administration of vaccines. So, the aim of this study was to assess oropharyngeal carriage rate of $N$. meningitidis, antibiotic susceptibility pattern and associated risk factors among primary school children in Gondar town, Northwest Ethiopia.

\section{Methods}

Study setting, design, and period

A community-based cross-sectional study was conducted among primary school children in Gondar town, North West Ethiopia, from January to April 2019. This study was conducted in six primary schools. Gondar is found 737 $\mathrm{km}$ from Addis Ababa, the capital city of Ethiopia, and $180 \mathrm{~km}$ from Bahir Dar, the capital of Amhara national regional state. Gondar town and its surroundings have 44 elementary schools, 11 secondary schools and 30 kindergartens.

\section{Sample size and sampling technique}

The sample size (524) was determined by using a single population proportion formula by considering the prevalence of $20.4 \%$ [8], with a $95 \%$ confidence interval, and a $5 \%$ margin of error, with $10 \%$ no-response rate and design effect. The multistage sampling technique was used to select schools. Then schools were stratified to grades and sections. The total number of study participants were allocated proportionally to each school, grades and sections based on the school sampling frame and the 
Table 1 List of selected elementary schools and number of selected students in Gondar town, Northwest Ethiopia, January to April, 2019

\begin{tabular}{|c|c|c|c|c|c|}
\hline S.no & $\begin{array}{l}\text { Elementary } \\
\text { school }\end{array}$ & $\begin{array}{l}\text { Students per } \\
\text { school }\end{array}$ & Proportion & $\begin{array}{l}\text { Proportionally allocated number of students per } \\
\text { school }\end{array}$ & $\begin{array}{l}\text { Number of students taken } \\
\text { (sample) }\end{array}$ \\
\hline 1 & Abiwotfire & 2010 & 23.4 & 128 & 120 \\
\hline 2 & Hubret & 1090 & 12.7 & 70 & 66 \\
\hline 3 & AtseBekafa & 1146 & 13.2 & 73 & 64 \\
\hline 4 & TsadikuYohanis & 1450 & 16.8 & 92 & 92 \\
\hline 5 & Meseret & 1512 & 17.6 & 97 & 94 \\
\hline 6 & Chechela & 1400 & 16.3 & 90 & 88 \\
\hline \multicolumn{2}{|l|}{ Total } & 8608 & 100 & 550 & 524 \\
\hline
\end{tabular}

study subjects were selected by simple random sampling technique (Table 1).

\section{Data collection and laboratory methods Data collection procedures}

A pre-tested questionnaire based on postulated or known risk factors was developed and modified to explore the objectives of the study. Then, it was checked on school children who were not included in the study. It was prepared in English and translated to Amharic then translated back into English to check the accuracy of the translation. The questionnaire design included two parts; socio-demographic characteristics and associated risk factors.

The questionnaire and assent/consent form were distributed to the selected students at school after informing the purpose of the study and the right of the study participants. Questionnaire and assent/consent form were also distributed to guardians and emphasis was given to return the questionnaire and assent/consent form after $24 \mathrm{~h}$. Students living alone (with the age range of 17-18 years) were considered as adults and informed to fill the questionnaire and sign the consent form at school. Socio-demographic characteristics and other relevant information filled by the parents/guardians and students were collected at school by trained laboratory technologists before sample collection.

\section{Laboratory methods}

\section{Oropharyngeal sample collection}

Oropharyngeal swabs were collected by a trained medical microbiologist using a plain cotton swab (Unison Narula, India) using tongue depressor (Unison Narula group, India) at the posterior pharyngeal wall behind the uvula and tonsils of each volunteer participant. After collection, samples were transported by using Amies transport media (Bio mark, India) to the University of Gondar teaching hospital laboratory within $2 \mathrm{~h}$ of collection within a cold box.

\section{Culture and identification}

Once the specimens reached to Gondar University teaching laboratory, it was inoculated on Modified Thayer Martin (MTM) culture media (Oxoid, UK). The inoculated MTM plates were incubated at $37^{\circ} \mathrm{C}$ with 5$10 \% \mathrm{CO}_{2}$ for 24 to $48 \mathrm{~h}$. A presumptive diagnosis was done by gram stain and colony characteristics on the agar plate. Medium to large, round, smooth, convex, colorless-to-grey, opaque colonies on the MTM was further confirmed by the oxidase test (Deben Diagnostics Ltd., UK). After confirmation, the presence of gramnegative diplococcus with oxidase-positive, isolates were sub-cultured on a blood agar plate (BAP) (Oxoid, UK) with $5-10 \% \mathrm{CO}_{2}$ for 24 to $48 \mathrm{~h}$, to guarantee the purity of colonies for the biochemical test. Plates were monitored every $24 \mathrm{~h}$ for the growth of typical colonies.

Carbohydrate utilization test (glucose, maltose, lactose, and sucrose) was performed by cystine trypticase agar (CTA) (SRL, India) to further differentiate Neisseria meningitidis from Moraxella species and other nonpathogenic Neisseria species. Isolates with gram-negative diplococci, oxidase-positive, glucose fermenter, maltose fermenter, lactose and sucrose none- fermenter were interpreted and confirmed as $N$. meningitidis. Once the species are known, the serogroup of isolates was determined with the slide agglutination method while using commercially prepared antiserum A, B, C, W135/Y, and $\mathrm{X}$ (Bio-Rad, France) and antiserum X (BD Difco, USA). Negative for these six serogroups was classified as nonserogroupable [8].

\section{Antimicrobial susceptibility testing}

Antimicrobial susceptibility testing was carried out on isolates of $N$. meningitidis by using disc diffusion technique as per the standard Kirby-Bauer method on Mueller-Hinton agar (Bio mark, India) supplemented with $5 \%$ sheep blood at $37^{\circ} \mathrm{C}$ for $18-24 \mathrm{~h}$ [11]. A suspension of the test organism was prepared equivalent to 0.5 McFarland. The surface of Mueller-Hinton agar supplemented with $5 \%$ sheep blood was completely covered by rotating the swab. The plates were allowed to dry for 3- 
$5 \mathrm{~min}$; then discs were evenly distributed on the inoculated plate using sterile forceps and incubated in $5-10 \%$ $\mathrm{CO}_{2}$ at $37^{\circ} \mathrm{C}$ for $20-24 \mathrm{~h}$. The following routinely used antimicrobial agents were tested: cefotaxime $(30 \mu \mathrm{g})$, minocycline $(30 \mu \mathrm{g})$ meropenem $(10 \mu \mathrm{g})$, azithromycin $(15 \mu \mathrm{g})$, ciprofloxacin $(5 \mu \mathrm{g})$, trimethoprim-sulfamethoxazole $(1.25 / 23.75 \mu \mathrm{g})$, chloramphenicol $(30 \mu \mathrm{g})$, and rifampin $(5 \mu \mathrm{g})$. Diameters of the zone of inhibition around the disc was measured to the nearest millimeter using a graduated caliper in millimeters and results were classified as sensitive, intermediate and resistant based on CLSI-2018 guideline [12]. Multidrug resistance was defined as resistance of an isolate to two or more antimicrobial classes tested [13].

\section{Laboratory data quality assurance}

Preanalytical, analytical and post analytical quality assurance was maintained [14].

\section{Data analysis and interpretation}

All data was entered to EPI info version 7 for data clearance and consistency and exported to SPSS version 20.0 for analysis. Descriptive statistics was computed to calculate frequencies. The magnitude of the association between different variables and oropharyngeal meningococcal carriage was assessed using bivariate and multivariate analysis. Variables which had a $P$ - value $\leq 0.20$ for bivariate analysis was taken to multivariate analysis to check real association of meningococcal carriage rate with risk factors and expressed by adjusted odds ratio at $95 \%$ confidence interval. A $P$-value $<0.05$ was considered as statistically significant. Data was summarized using numbers, percentages and tables.

\section{Ethical considerations}

The study was conducted after obtaining institutional ethical clearance ("Ref No-SBMLS/2123/11") from University of Gondar. Support letter was sought from Gondar town educational office. Assent from the parents/ guardians of youth students and assent/consent from the study participants was obtained.

\section{Results}

\section{Demographic characteristics of study participants}

A total of 524 school children (283 males and $241 \mathrm{fe}$ males) were included in this study. The mean \pm SD age of the participants was $12.2 \pm 2.74$ years. About $49 \%$ of the study participants were within the age group of 1114 years (Table 2).

\section{Oropharyngeal carriage isolates}

The overall prevalence of Neisseria meningitidis was 53(10.1\%) (95\% CI: 7.6, 12.8). Meningococcal carriage identified among male 30/53 (56.6\%) was higher than females 23/53 (43.4\%) (Table 3).
Table 2 Socio-demographic characteristics of all participants among primary school children in Gondar town, Northwest Ethiopia, January to April 2019

\begin{tabular}{|c|c|c|}
\hline Characteristics of children $(\boldsymbol{n}=524)$ & Frequency & $\%$ \\
\hline \multicolumn{3}{|c|}{ Sex } \\
\hline Male & 283 & $54 \%$ \\
\hline Female & 241 & $46 \%$ \\
\hline \multicolumn{3}{|c|}{ Age } \\
\hline $7-10$ & 148 & $28.2 \%$ \\
\hline $11-14$ & 257 & $49 \%$ \\
\hline $15-18$ & 119 & $22.7 \%$ \\
\hline \multicolumn{3}{|c|}{ Religion } \\
\hline Orthodox & 419 & $80.0 \%$ \\
\hline Muslim & 100 & $19.1 \%$ \\
\hline Protestant & 2 & $0.4 \%$ \\
\hline Catholic & 1 & $0.2 \%$ \\
\hline Other & 2 & $0.4 \%$ \\
\hline \multicolumn{3}{|c|}{ Residence } \\
\hline Rural & 10 & $1.9 \%$ \\
\hline Urban & 514 & $98.1 \%$ \\
\hline \multicolumn{3}{|c|}{ Grade level } \\
\hline $1-4$ & 253 & $48.3 \%$ \\
\hline $5-8$ & 271 & $51.7 \%$ \\
\hline
\end{tabular}

\section{Serogroup distribution of $N$. meningitidis}

All types of invasive meningococcal serogroups were identified, of which, serogroup A was the leading isolate with the isolation rate of $13(24.5 \%)$ followed by serogroup Y/W135, 11(20.7\%). Serogroup B, 4 (7.5\%) was the least identified isolate. Serogroup A dominates on male $(15.1 \%)$ than female (9.4\%) (Table 4$)$.

\section{Antimicrobial susceptibility patterns of $N$. meningitidis} Neisseria. meningitidis isolates were tested against routinely used antimicrobial agents. In this study, most of the meningococci isolates showed a high level of resistance to trimethoprim/ sulfamethoxazole (73.6\%), ciprofloxacin (45.3\%) and cefotaxime (35.8\%). However, the majority of the isolates were susceptible to azithromycin (96.2\%), chloramphenicol (92.5\%) and minocycline (88.7\%) (Table 5).

\section{Multidrug resistance pattern of $N$. meningitidis}

Multidrug resistance pattern of $N$. meningitis isolates was also determined. Overall, most of the meningococcal isolates showed a high level of multidrug resistance with the rate of $32(60.4 \%)$. On the serogroup level, serogroup 
Table 3 Distribution of oropharyngeal isolates by age, sex and school among primary school children in Gondar town, Northwest Ethiopia, January to April 2019

\begin{tabular}{|c|c|c|c|}
\hline \multirow[t]{2}{*}{ School } & \multirow[t]{2}{*}{ Age } & \multicolumn{2}{|c|}{ N. meningitides $(N=53)$} \\
\hline & & M & $\mathrm{F}$ \\
\hline \multirow[t]{3}{*}{ Abiwot fire } & $7-10$ & 1 & 0 \\
\hline & $11-14$ & 3 & 0 \\
\hline & $15-18$ & 6 & 0 \\
\hline \multirow[t]{3}{*}{ Hibret } & $7-10$ & 0 & 1 \\
\hline & $11-14$ & 1 & 2 \\
\hline & $15-18$ & 0 & 3 \\
\hline \multirow[t]{3}{*}{ AtseBekafa } & $7-10$ & 0 & 1 \\
\hline & $11-14$ & 0 & 4 \\
\hline & $15-18$ & 0 & 0 \\
\hline \multirow[t]{3}{*}{ TsadikuYohanis } & $7-10$ & 5 & 4 \\
\hline & $11-14$ & 1 & 5 \\
\hline & $15-18$ & 0 & 0 \\
\hline \multirow[t]{3}{*}{ Meseret } & $7-10$ & 1 & 0 \\
\hline & $11-14$ & 7 & 0 \\
\hline & $15-18$ & 3 & 0 \\
\hline \multirow[t]{3}{*}{ Chechela } & $7-10$ & 0 & 0 \\
\hline & $11-14$ & 2 & 2 \\
\hline & $15-18$ & 0 & 1 \\
\hline Total n (\%) & & $30(56.6)$ & $23(43.4)$ \\
\hline
\end{tabular}

B was $100 \%$ MDR followed by serogroup X, $80 \%$ and serogroup Y/W-135, 72.7\%. Only 9 (16.9\%) of the meningococcal isolates had no resistance for all class of antimicrobials tested. Similarly, about $50 \%$ of nonserogroupable (NG) isolates had no resistance to the tested class of antimicrobials (Table 6).

\section{Associated risk factors of study participants}

In this study, the average family size of students was 5.3 people per household and the average number of rooms per household was 2.3. From all study participants, 21\% had a history of hospitalization at least for 1 day at health institutions. Of the total participants, the majority of $(60.5 \%)$ had a history of tonsillectomy. Among the study participants who had a history of treatment before 2 weeks of the study period, $19.3 \%$ had poor treatment adherence. About $10.1 \%$ of the family of the study participants smokes cigarettes while $29.2 \%$ of the family had a history of living in crowded area (Table 7).

\section{Risk factors analysis for oropharyngeal carriage of $\mathrm{N}$. meningitidis}

In bivariable logistic regression analysis associated factors with $P$-value $<0.2$ were transferred to multivariable logistic regression to the significant association of these factors. Multivariable logistic statistical analysis showed that $N$. meningitidis oropharyngeal carriage had a significant association with family size (Adjusted Odds Ratio (AOR; $2.7195 \%$ CI 1.41-5.18, $P=0.003)$ ), sharing utensils (AOR; 4.15, 95\% CI 1.49-11.58, $P=0.007$ ), attending healthcare institutions (AOR;2.76, 95\% CI 1.098-6.94, $P=0.031$ ), history of tonsillectomy (AOR;2.84, 95\% CI $1.36-5.93, P=0.006$ ), indoor kitchen (AOR;5.55, 95\% CI, 1.53-20.17 $P=0.009$ ), parental cigarette smoking (AOR; 4.62, 95\% CI,1.65-12.89, $P=0.004)$ and number of students per classroom (AOR;7.81, 95\% CI, 1.02 59.78, $P=$ 0.048) (Table 7).

\section{Discussion}

Invasive meningococcal infection is a global problem occurring as sporadic, hyper-sporadic, and epidemic disease [15]. The problem has mainly occurred in the developing world especially in the African meningitis belt $[16,17]$. In Ethiopia, meningitis outbreaks have been occurred over several years, being responsible for morbidity and mortality [7]. Many researched evidences showed that people who are carriers of $N$. meningitidis are at high risk of developing invasive meningococcal disease in their life time specifically, if they are exposed to factors that wanes the immune system. However, in Ethiopia, there is only limited information regarding the $N$. meningitidis carriage rate, antimicrobial susceptibility pattern and associated factors [4, 18]. Therefore, this study was intended to show the gap and fill the limited information on the oropharyngeal carriage, antimicrobial

Table 4 Serogroup distribution of N. meningitidis isolates by age and sex among primary school children in Gondar town, Northwest Ethiopia, January to April 2019

\begin{tabular}{|c|c|c|c|c|c|c|c|c|c|c|c|c|c|}
\hline \multirow[t]{3}{*}{ Age } & \multicolumn{12}{|c|}{ Serogroups $(\boldsymbol{N}=53)$} & \multirow{3}{*}{$\begin{array}{l}\text { Total n } \\
\text { (\%) }\end{array}$} \\
\hline & \multicolumn{2}{|c|}{$\mathrm{A}(n=13)$} & \multicolumn{2}{|c|}{$\mathrm{B}(n=4)$} & \multicolumn{2}{|c|}{$C(n=8)$} & \multicolumn{2}{|c|}{ Y/W135 = 11} & \multicolumn{2}{|c|}{$X(n=5)$} & \multicolumn{2}{|c|}{$\mathrm{NG}(n=12)$} & \\
\hline & $\mathrm{M}$ & $\mathrm{F}$ & M & $\mathrm{F}$ & $\mathrm{M}$ & $\mathrm{F}$ & $\mathrm{M}$ & $\mathrm{F}$ & $M$ & $\mathrm{~F}$ & M & $\mathrm{F}$ & \\
\hline $7-10$ & 0 & 2 & 2 & 0 & 2 & 0 & 1 & 1 & 1 & 2 & 1 & 1 & $13(24.5)$ \\
\hline $11-14$ & 6 & 3 & 1 & 1 & 2 & 3 & 2 & 3 & 0 & 0 & 3 & 3 & $27(50.9)$ \\
\hline $15-18$ & 2 & 0 & 0 & 0 & 1 & 0 & 2 & 2 & 1 & 1 & 3 & 1 & $13(24.5)$ \\
\hline Total (\%) & $8(15.1)$ & $5(9.4)$ & $3(5.7)$ & $1(1.9)$ & $5(9.4)$ & $3(5.7$ & $5(9.4$ & $6(11.3)$ & $2(3.8)$ & $3(5.7)$ & $7(13.2)$ & $5(9.4)$ & $53(100)$ \\
\hline
\end{tabular}


Table 5 Antimicrobial susceptibility patterns of meningococcal isolates among primary school children in Gondar town, Northwest Ethiopia, January to April 2019

\begin{tabular}{|c|c|c|c|c|c|c|c|c|}
\hline \multirow[t]{2}{*}{ Antimicrobials } & \multirow[t]{2}{*}{ Sensitivity } & \multicolumn{7}{|c|}{ N. meningitidis $(n=53)$} \\
\hline & & $A=13$ & $B=4$ & $C=8$ & $W / Y=11$ & $x=5$ & $N G=12$ & Total $(=53)$ n (\%) \\
\hline \multirow[t]{2}{*}{ Cefotaxime } & $S$ & 8 & 1 & 7 & 5 & 3 & 10 & $34(64.2)$ \\
\hline & $\mathrm{R}$ & 5 & 3 & 1 & 6 & 2 & 2 & 19 (35.8) \\
\hline \multirow[t]{2}{*}{ Minocycline } & $S$ & 9 & 3 & 8 & 10 & 5 & 12 & $47(88.7)$ \\
\hline & $\mathrm{R}$ & 4 & 1 & & 1 & & & $6(11.3)$ \\
\hline \multirow[t]{2}{*}{ Meropenem } & $S$ & 10 & 3 & 8 & 9 & 5 & 10 & $45(84.9)$ \\
\hline & $\mathrm{R}$ & 3 & 1 & & 2 & & 2 & $8(15.1)$ \\
\hline \multirow[t]{2}{*}{ Azithromycin } & $S$ & 12 & 4 & 8 & 10 & 5 & 12 & $51(96.2)$ \\
\hline & $\mathrm{R}$ & 1 & & & 1 & & & $2(3.8)$ \\
\hline \multirow[t]{3}{*}{ Ciprofloxacin } & $S$ & 7 & 2 & 6 & 4 & 2 & 7 & $28(52.8)$ \\
\hline & 1 & & & & 1 & & & $1(1.9)$ \\
\hline & $\mathrm{R}$ & 6 & 2 & 2 & 6 & 3 & 5 & $24(45.3)$ \\
\hline \multirow[t]{3}{*}{ Trimethoprim/ sulfamethoxazole } & $S$ & 1 & & 1 & 3 & & 5 & $10(18.9)$ \\
\hline & I & 1 & & & & 1 & 2 & $4(7.5)$ \\
\hline & $\mathrm{R}$ & 11 & 4 & 7 & 8 & 4 & 5 & 39 (73.6) \\
\hline \multirow[t]{3}{*}{ Chloramphenicol } & $S$ & 13 & 3 & 8 & 8 & 5 & 12 & $49(92.5)$ \\
\hline & I & & & & 1 & & & $1(1.9)$ \\
\hline & $\mathrm{R}$ & & 1 & & 2 & & & $3(5.7)$ \\
\hline \multirow[t]{3}{*}{ Rifampin } & $\mathrm{S}$ & 8 & 2 & 7 & 8 & 5 & 9 & 39 (73.6) \\
\hline & । & 2 & & 1 & & & 1 & $4(7.5)$ \\
\hline & $\mathrm{R}$ & 3 & 2 & & 2 & & 2 & $9(17)$ \\
\hline
\end{tabular}

A Serogrup A, B Serogroup B, C Serogroup C, W/Y Serogroup W/Y, X Serogroup X, NG Non-serogroupable, S Sensitive, $R$ Resistance, I Intermediate

Table 6 Multi-drug resistance pattern for Neisseria meningitidis isolates among primary school children in Gondar town, Northwest Ethiopia, January to April 2019

\begin{tabular}{lllllllll}
\hline Serogroup & \multicolumn{9}{l}{ Anti-microbial sensitivity } & pattern & Total & \multicolumn{1}{l}{$M$ MDR $\geq 2$ class } \\
\cline { 2 - 6 } & R0 & R1 & R2 & R3 & R4 & $>$ R5 & & n/N (\%) \\
\hline A & 1 & 3 & 2 & 3 & 3 & 1 & 13 & $9 / 13(69.2)$ \\
B & 0 & 0 & 2 & 1 & 0 & 1 & 4 & $4 / 4(100)$ \\
C & 1 & 5 & 1 & 1 & 0 & 0 & 8 & $2 / 8(25)$ \\
Y/W135 & 1 & 2 & 3 & 2 & 1 & 2 & 11 & $8 / 11(72.7)$ \\
X & 0 & 1 & 4 & 0 & 0 & 0 & 5 & $4 / 5(80)$ \\
NG & 6 & 1 & 1 & 3 & 1 & 0 & 12 & $5 / 12(41.7)$ \\
Total & 9 & 12 & 13 & 10 & 5 & 4 & 53 & $32 / 53(60.4)$ \\
Percentile & $\mathbf{1 6 . 9}$ & $\mathbf{2 2 . 7}$ & $\mathbf{2 4 . 5}$ & $\mathbf{1 8 . 9}$ & $\mathbf{9 . 4}$ & $\mathbf{7 . 6}$ & $\mathbf{1 0 0}$ & $\mathbf{6 0 . 4}$
\end{tabular}

$R 0$ No resistance for any class of antimicrobial, $R 1$ Resistance for one class of antimicrobials, $R 2$ Resistance for two class of antimicrobial, $R 3$ Resistance for three class of antimicrobials, $R 4$ Resistance for four class of antimicrobials $R>5$ Resistance for five class of antimicrobials resistance pattern and associated risk factors for $N$. meningitidis especially in school children in the study area.

The overall $N$. meningitidis oropharyngeal carriage rate in this study was $10.1 \%$. The predominant serogroup in our study was serogroup A (24.5\%) and W135/Y (20.6\%) while the least was serogroup B (7.6\%). Despite the fact that menA vaccine mass vaccination campaign was implemented in 2012 in the study area, now it is 6 years after implementation and the prevalence of $N$. meningitidis serotype A will be reverted to high. The high prevalence of serotype W135/Y may be due to suppression of serotype A by the vaccine which in turn let serotype W135/Y to compete with other least prevalent serotypes. This overall carriage prevalence was markedly higher than a study conducted at Gondar University teaching hospital in 2012 (234 oropharyngeal swabs) among < 10 years OPD patients with $6 \%$ carriage [19]. The variation may result from the difference in the target population (asymptomatic vs symptomatic), time of investigation and sample size.

Our study also had a high prevalence of carriage than the studies conducted in Arba Minch, Southern Ethiopia among 7479 oropharyngeal samples with 6.6\% 
Table 7 Bivariate and multivariate analysis of risk factors for oropharnygeal carriage among primary school children in Gondar town, Northwest Ethiopia, January to April 2019

\begin{tabular}{|c|c|c|c|c|c|}
\hline \multirow[t]{2}{*}{ Variables } & \multicolumn{2}{|c|}{ N. meningitidis } & \multirow[t]{2}{*}{ COR (95\% C.I.) } & \multirow[t]{2}{*}{ AOR (95\% C.I.) } & \multirow[t]{2}{*}{$P$-value } \\
\hline & Yes n(\%) & No n(\%) & & & \\
\hline \multicolumn{6}{|l|}{ Sex } \\
\hline Male & $30(10.6)$ & $253(89.4)$ & $1.12(0.634-1.99)$ & - & - \\
\hline Female & $23(9.5)$ & $218(90.5)$ & 1 & - & - \\
\hline \multicolumn{6}{|l|}{ Age } \\
\hline $7-10$ & $13(8.8)$ & $135(91.2)$ & $1.274(0.567-2.86)$ & - & - \\
\hline $11-14$ & $27(10.5)$ & $230(89.5)$ & $1.045(0.519-2.105)$ & - & - \\
\hline $15-18$ & $13(10.9)$ & $106(89.1)$ & 1 & - & - \\
\hline \multicolumn{6}{|l|}{ Grade level } \\
\hline $1-4$ & $24(9.5)$ & $229(90.5)$ & $0.875(0.494-1.55)$ & - & - \\
\hline $5-8$ & $29(10.7)$ & $242(89.3)$ & 1 & - & - \\
\hline \multicolumn{6}{|l|}{ Family size } \\
\hline$>5$ & $29(13.9)$ & $180(86.1)$ & $1.953(1.103-3.46)$ & $2.71(1.41-5.18)$ & 0.003 \\
\hline$\leq 5$ & $24(7.6)$ & $291(92.4)$ & 1 & 1 & \\
\hline \multicolumn{6}{|c|}{ Number of beds/ houses } \\
\hline Only one & $42(10.5)$ & 360 (89.6) & $1.18(0.586-2.364)$ & - & - \\
\hline > one & $11(9)$ & $111(91)$ & 1 & - & - \\
\hline \multicolumn{6}{|c|}{ Sharing utensils } \\
\hline Yes & $48(12.1)$ & $349(87.9)$ & $3.356(1.31-8.62)$ & $4.15(1.49-11.58)$ & 0.007 \\
\hline No & $5(3.9)$ & $122(96.1)$ & 1 & 1 & \\
\hline \multicolumn{6}{|c|}{ History of family visiting crowded area } \\
\hline Yes & $16(10.5)$ & $137(89.5)$ & $1.05(0.568-1.958)$ & - & - \\
\hline No & $37(9.97)$ & $334(90.03)$ & 1 & - & - \\
\hline \multicolumn{6}{|c|}{ Visiting healthcare institutions } \\
\hline Yes & $46(11.4)$ & $358(88.6)$ & $2.07(0.911-4.723)$ & $2.76(1.098-6.94)$ & 0.031 \\
\hline No & $7(5.8)$ & $113(94.2)$ & 1 & - & - \\
\hline \multicolumn{6}{|c|}{ Hospitalization } \\
\hline Yes & $14(12.7)$ & $96(87.3)$ & $1.40(0.732-2.687)$ & - & - \\
\hline No & $39(9.4)$ & $375(90.6)$ & 1 & - & - \\
\hline \multicolumn{6}{|c|}{ Antibiotics adherence } \\
\hline Yes & $39(12.1)$ & $384(87.9)$ & 1 & - & - \\
\hline No & $14(13.9)$ & $87(86.1)$ & $1.584(0.824-3.05)$ & - & - \\
\hline \multicolumn{6}{|c|}{ Tonsillectomy } \\
\hline Yes & $40(12.6)$ & $277(87.4)$ & $2.155(1.123-4.136)$ & $2.84(1.36-5.93)$ & 0.006 \\
\hline No & $13(6.3)$ & $194(93.7)$ & 1 & 1 & \\
\hline \multicolumn{6}{|c|}{ Kitchen location } \\
\hline Indoor & $50(11.7)$ & $379(88.3)$ & $4.046(1.234-13.26)$ & $5.55(1.53-20.17)$ & 0.009 \\
\hline Outdoor & $3(3.2)$ & $92(96.8)$ & 1 & 1 & \\
\hline \multicolumn{6}{|c|}{ Passive smoker } \\
\hline Yes & $8(15.1)$ & $45(84.9)$ & $1.68(1.25-6.82)$ & $4.62(1.65-12.89)$ & 0.004 \\
\hline No & $45(9.6)$ & $426(90.4)$ & 1 & 1 & \\
\hline \multicolumn{6}{|c|}{ Number of students per class } \\
\hline$\leq 40$ & $1(1.7)$ & $57(98.3)$ & 1 & 1 & \\
\hline
\end{tabular}


Table 7 Bivariate and multivariate analysis of risk factors for oropharnygeal carriage among primary school children in Gondar town, Northwest Ethiopia, January to April 2019 (Continued)

\begin{tabular}{llllll}
\hline Variables & \multicolumn{2}{l}{ N. meningitidis } & & COR (95\% C.I.) & AOR (95\% C.I.) \\
\cline { 2 - 4 } & Yes n(\%) & No n(\%) & & \\
\hline$>40$ & $52(11.2)$ & $414(88.8)$ & $7.159(0.971-52.79)$ & $7.81(1.02-59.78)$ \\
\hline
\end{tabular}

prevalence [20] and in Gurage Zone, Southern Ethiopia with $4.6 \%$ carriage rate [21]. Surveillance of invasive meningitis isolates in Ethiopia in 2012-2013 showed that in Hawassa, in the southern part of the country, serogroup A was the dominant cause of disease [22]. But in 2015, menA vaccine was given and this may be the reason for the decrement of the carriage rate. On those mentioned studies, no serogroup A was identified and serogroup B was the least identified. Implementation of menA mass vaccination campaign may be the reason for zero prevalence of serotype A.

In contrast, our study had less carriage rate compared to three local studies conducted at Gondar university hospital (2019 CSF samples) in the year 2011 to 2013 with 18.4\% prevalence [23], Addis Ababa (240 nasal swabs) with $20.4 \%$ carriage rate [8] and bacterial meningitis surveillance in Ethiopia, 2012-2013 (139 CSF samples) with $19.4 \%$ prevalence rate [24].

The antimicrobial susceptibility pattern of $N$. meningitidis was determined. In the present study, higher resistance was reported for cefotaxime (35.8\%), ciprofloxacin $(45.3 \%)$ and trimethoprim-sulfamethoxazole (73.6\%). The increment of resistance may be due to the easy accessibility of drugs, the simplicity of taking drugs (oral route of administration) and the use of these antibiotics for a long period of time in the country especially ciprofloxacin and trimethoprim-sulfamethoxazole and on top of that, irrational drug use. Many studies done in developed countries showed that resistance to cefotaxime is rare. But, in the Southern parts of Ethiopia about 14\% of cefotaxime resistance was reported which supports our findings [21].

Ciprofloxacin was another antimicrobial agent tested against $\mathrm{N}$. meningitidis and high level of resistance (45\%). In contrary to our study, in Addis Ababa [8] and Gondar [19], N. meningitidis was susceptible to ciprofloxacin with the rate of 83.7 and $78.6 \%$ respectively. This discrepancy might be due to the difference in antimicrobial usage practices.

In our study, associated risk factors like tonsillectomy $(P=0.006)$, large family size $(P=0.003)$, history of visiting health care institutions $(P=0.031)$, number of students per class greater than $40 \quad(P=0.048)$, indoor kitchen location $(P=0.009)$, sharing utensils $(P=0.007)$, and cigarette smoking $(P=0.004)$ were significantly associated with $N$. meningitidis carriage. In different studies determinants like family size [25], crowded living condition $[8,26]$, the number of children per house [27], the number of positive household members [28], lower socioeconomic status [29], indoor kitchen [26], and overcrowding in the house [30] were significantly associated risk factors in which coincided with our study finding.

\section{Conclusion}

Neisseria meningitidis prevalence in the present study had a high carriage rate among males than females. Serogroup A and Y/W135 were predominantly circulating meningococcal isolates in the community. Meningococcal carriage rate among primary school students was significantly associated with larger family size, students with tonsillectomy, parental cigarette smoking, students with greater than 40 per class, sharing utensils, history of visiting healthcare institutions and indoor kitchen.

The antibiotics markedly resisted by meningococcal isolates were trimethoprim-sulfamethoxazole, ciprofloxacin, and cefotaxime. The effective antibiotics identified in this study were minocycline, azithromycin, meropenem and chloramphenicol. Most of the meningococcal isolates were identified as multidrug resistance, with serogroup B and serogroup X had markedly higher resistance. We recommend the scientific community as well as the health sector to perform continuous surveillance of $N$. meningitidis carriage to control any possible diversity and emerging virulent strains in high-risk populations as well as to predict the epidemiology of meningococcal infections and the clinical spectrum of affected populations. Especially, molecular identification is essential for identification of which genotypes is circulating. Health education should be strengthened to reduce $N$. meningitidis carriage and possible risk factors. Moreover, antibiotic stewardship should be well strengthened at all health facility level to reduce the expanding of drug resistance problem.

\section{Abbreviations}

ATCC: American Type Culture Collection; BAP: Blood Agar Plate; CLSI: Clinical Laboratory Standard Institute; CSF: Cerebro Spinal Fluid; CTA: Cysteine

Trypticase Agar; ELISA: Enzyme Linked Immuno-Sorbent Assay; MTM: Modified Thayer-Martín Media; OPD: Out-Patient Department; PCR: Polymerase Chain Reaction; SBML: School of Biomedical and Laboratory Science

\section{Acknowledgments}

The authors would like to thank all the study participants and parents for their good collaboration. The authors would like to thank the department of Medical Microbiology, School of Biomedical and Laboratory Science, College 
of Medicine and Health Sciences, University of Gondar for logistic and material supports. Finally, the authors would like to thank Ethiopian Public Health Institute for reagent support.

\section{Authors' contributions}

ZT did conceptualization, analyzing the data, methodology designing, investigation during the laboratory work, writing original draft and review the final manuscript. FM did conceptualization, methodology designing, writing original draft and review the final manuscript. MT did conceptualization, analyzing the data, methodology designing, writing original draft and review the final manuscript. TB did conceptualization, methodology designing, investigation during the laboratory work, writing original draft and review the final manuscript. All authors have read and approved the manuscript.

\section{Funding}

This study was not funded.

\section{Availability of data and materials}

The datasets used and/or analyzed during the current study are available from the corresponding author on reasonable request.

\section{Ethics approval and consent to participate}

An ethical clearance letter was obtained from the Departmental Research and Ethics Review Committee of school of biomedical laboratory science. The reference number of the ethical letter was "Ref no- SBMLS/2123/11". This ethical letter was obtained from Mr. Mekonnen Girma (mekonnen2302 @cmail.com), Markos Negash (markosnegash@yahoo.com) and Bamilaku Enawgaw (bamlak21@gmail.com). Written consent was obtained from participants and informed as their participation was voluntary. Study participants were also informed about the purpose of the study. Confidentiality was maintained at all levels of the study. In addition, study participants involvement was based on a voluntary basis and participants who were unwilling to take part in the study and those who need to quit their participation at any stage were informed to do so without any restriction. Consent to participate was obtained from the parents/quardians of study participants under the age of 16 .

\section{Consent for publication}

All authors read the manuscript and have provided their consent to publish.

\section{Competing interests}

The authors declare that they have no competing interest.

\section{Author details}

${ }^{1}$ Kemissie General Hospital, Kemise, Northeast, Ethiopia. ${ }^{2}$ Department of Medical Microbiology, College of Medicine and Health Sciences, Bahir Dar University, Bahir Dar, Ethiopia. ${ }^{3}$ Department of Medical Microbiology, School of Biomedical and Laboratory Sciences, College of Medicine and Health Sciences, University of Gondar, Gondar, Ethiopia.

Received: 12 July 2019 Accepted: 11 May 2020

\section{Published online: 20 May 2020}

\section{References}

1. Trivedi K, Tang CM, Exley RM. Mechanisms of meningococcal colonization. Trends Microbiol. 2011;19(9):456-63.

2. Caugant DA, Maiden MC. Meningococcal carriage and disease-population biology and evolution. Vaccine. 2009;27:B64-70.

3. Montero-Martin M, Inwald DP, Carrol ED, Martinon-Torres F. Prognostic markers of meningococcal disease in children: recent advances and future challenges. Expert Rev Anti-Infect Ther. 2014;12(11):1357-69.

4. Gazi H, Surucuoglu S, Ozbakkaloglu B, Akcali S, Ozkutuk N, Degerli K, et al. Oropharyngeal carriage and penicillin resistance of Neisseria meningitidis in primary school children in Manisa, Turkey. Ann Acad Med Singapore. 2004; 33(6):758-62.

5. Rouphael NG, Stephens DS. Neisseria meningitidis: biology, microbiology, and epidemiology. Methods Mol Biol. 2012;799:1-20.

6. Exner M, Bhattacharya S, Christiansen B, Gebel J, Goroncy-Bermes P, Hartemann $P$, et al. Antibiotic resistance: what is so special about multidrugresistant Gram-negative bacteria? GMS Hyg Infect Control. 2017;12:Doc05.
7. Ethiopian Health and Nutrition Research Institute Federal Democratic Republic of Ethiopia. National guideline on meningococcal meningitis surveillance and outbreak management. Addis Ababa: Ethiopia Public Health Institute (EPHI); 2013.

8. Alemayehu T, Mekasha A, Abebe T. Nasal carriage rate and antibiotic susceptibility pattern of Neisseria meningitidis in healthy Ethiopian children and adolescents: a cross-sectional study. PLoS One. 2017;12(10):e0187207.

9. Goldblatt D. Conjugate vaccines. Clin Exp Immunol. 2000;119:1-3.

10. Djingarey MH, Diomande FV, Barry R, Kandolo D, Shirehwa F, Lingani C, et al. Introduction and rollout of a new group A meningococcal conjugate vaccine (PSA-TT) in African meningitis belt countries, 2010-2014. Clin Infect Dis. 2015;61(Suppl 5):S434-41.

11. Winn WC. Koneman's color atlas and textbook of diagnostic microbiology: Lippincott Williams \& Wilkins; 2006.

12. CLSI. Performance standards for antimicrobial susceptibility testing. In: CLS supplement M100. 28th ed. Wayne: Clinical and Laboratory Standards Institute; 2018.

13. Magiorakos AP, Srinivasan A, Carey RB, Carmeli Y, Falagas ME, Giske CG, et al. Multidrug-resistant, extensively drug-resistant and pandrug-resistant bacteria: an international expert proposal for interim standard definitions for acquired resistance. Clin Microbiol Infect. 2012;18:268-81.

14. Aminu A, Yahaya S. Carriage rate of Neisseria meningitides among pupils of islamic boarding schools (Tsangaya Almajirai) in Kano, Nigeria. Bayero J Pure Appl Sci. 2017;10(1):239-42.

15. Jafri RZ, Ali A, Messonnier NE, Tevi-Benissan C, Durrheim D, Eskola J, et al. Global epidemiology of invasive meningococcal disease. Popul Health Metrics. 2013;11(1):17.

16. Basta NE, Berthe A, Keita M, Onwuchekwa U, Tamboura B, Traore A, et al. Meningococcal carriage within households in the African meningitis belt: a longitudinal pilot study. J Infect. 2018;76(2):140-8.

17. Harrison LH, Pelton SI, Wilder-Smith A, Holst J, Safadi MA, Vazquez JA et al. The global meningococcal initiative: recommendations for reducing the global burden of meningococcal disease. Vaccine. 2011; 29(18):3363-71.

18. Soriani M. Unraveling Neisseria meningitidis pathogenesis: from functional genomics to experimental models. F1000Res. 2017;6:1228.

19. Assefa A, Gelaw B, Shiferaw Y, Tigabu Z. Nasopharyngeal carriage and antimicrobial susceptibility pattern of streptococcus pneumoniae among pediatric outpatients at Gondar University Hospital, North West Ethiopia. Pediatr Neonatol. 2013;54(5):315-21.

20. Bårnes GK, Kristiansen PA, Beyene D, Workalemahu B, Fissiha P, Merdekios B, et al. Prevalence and epidemiology of meningococcal carriage in Southern Ethiopia prior to implementation of MenAfriVac, a conjugate vaccine. BMC Infect Dis. 2016;16(1):639.

21. Fikerte $M$, Zelalem M, Biruk $Y$, Hiwot $T$, Melaku $Y$, Marechign $Y$. Antibiotic susceptibility pattern of Neisseria meningitides isolates from asymptomatic carriers in Gurage zone, Southern Ethiopia. Am J Health Res. 2019;7(1):12-8.

22. Bogaert $D$, Hermans $P$, Boelens $H$, Sluijter $M$, Luijendijk $A$, Rümke $H$, et al. Epidemiology of nasopharyngeal carriage of Neisseria meningitidis in healthy Dutch children. Clin Infect Dis. 2005;40(6):899-902.

23. Tegene B, Kassahun Denekew GM. Phenotypic characterization and serotypes identification of CSF isolates in acute bacterial meningitis. Am J Infect Dis. 2017:5(3):100-5.

24. Mihret W, Lema T, Merid Y, Kassu A, Abebe W, Moges B, et al. Surveillance of bacterial meningitis, Ethiopia, 2012-2013. Emerg Infect Dis. 2016;22(1):75.

25. Valipour M, Piroozmand A, Khorshidi A, Akbari $H$, Mirzaee $H$. Identification of serological groups A, B, C, W135, Y, X Neisseria meningitidis carriers by multiplex PCR in the nasopharynx of students in Kashan during 2011-2012. Feyz J Kashan Univ Med Sci. 2013;17(2):181-7.

26. Diallo K, Trotter C, Timbine Y, Tamboura B, Sow SO, Issaka B, et al. Pharyngeal carriage of Neisseria species in the African meningitis belt. J Infect. 2016;72(6):667-77.

27. Díaz J, Cárcamo M, Seoane M, Pidal P, Cavada G, Puentes $R$, et al. Prevalence of meningococcal carriage in children and adolescents aged 1019 years in Chile in 2013. J Infect Public Health. 2016;9(4):506-15.

28. De Moraes JC, Kemp B, De Lemos APS, Gorla MCO, Marques EGL, do Carmo Ferreira $\mathrm{M}$, et al. Prevalence, risk factors and molecular characteristics of meningococcal carriage among Brazilian adolescents. Pediatr Infect Dis J. 2015;34(11):1197-202 
29. Cleary P, Calvert N, Gee S, Graham C, Gray S, Kaczmarski E, et al. Variations in Neisseria meningitidis carriage by socioeconomic status: a cross-sectional study. J Public Health. 2015;38(1):61-70.

30. Nunes AMPB. Colonização por Neisseria meningitidis entre adolescentes após introdução da vacina meningocócica C conjugada em Salvador, Brasil; 2017

\section{Publisher's Note}

Springer Nature remains neutral with regard to jurisdictional claims in published maps and institutional affiliations.

Ready to submit your research? Choose BMC and benefit from:

- fast, convenient online submission

- thorough peer review by experienced researchers in your field

- rapid publication on acceptance

- support for research data, including large and complex data types

- gold Open Access which fosters wider collaboration and increased citations

- maximum visibility for your research: over $100 \mathrm{M}$ website views per year

At $\mathrm{BMC}$, research is always in progress.

Learn more biomedcentral.com/submissions 